\title{
ADJUSTMENT FOR THE OPTIMUM DISTRIBUTION OF DUST AND GAS IN FULLY MECHANIZED HEADING FACE
}

\author{
GONG, X. Y. - ZHANG, X. Y.* - XIA, Z. X. - WU, Y. - XUE, H. \\ Xi'an University of Science and Technology, 58 Yanta Road, Xi'an, China \\ (phone: +86-180-0921-8713) \\ *Corresponding author \\ e-mail:516437848@qq.com; phone:+86-136-4921-4724 \\ (Received $13^{\text {th }}$ Apr 2018; accepted $11^{\text {th }}$ Jul 2018)
}

\begin{abstract}
The forcing type ventilation at the current fully mechanized heading face is inadequate to meet the requirement of underground coal mine, which could lead to serious disaster of dust and gas explosion and environmental pollution in the roadway. In this paper, the airflow field, dust field and gas field at different distances from the duct outlet to the heading face were numerically simulated, the formation mechanism of each field and the reasons of unreasonable distribution were analyzed, an airflow adaptation adjustment method was proposed for realizing the optimal distribution of airflow, dust and gas by comprehensively changing the position, caliber and direction angle of the duct outlet. The method was applied to Ningtiaota coal mine in Northern Shaanxi of China. The adjustment schemes obtained with airflow adaptability adjustment method provided better results when prepared to before optimization. The dust concentration at the driver position decreased by $35 \%$ and the gas concentration reduced by $54 \%$, which provides a theoretical basis for the scientific management of ventilation in the fully mechanized heading face.
\end{abstract}

Keywords: duct outlet, airflow field, dust field, gas field, optimal adjustment of airflow

\section{Introduction}

The fully mechanized heading face is vulnerable to the severe disaster of dust and gas explosion. Currently, the expansion of cross-section size and overlong distance excavation contribute to the dust and gas accumulation and severely pollute the underground working environment (Zhou et al., 2017; Wang and Ren, 2013). The caliber and the distance between the outlet and heading face of traditional forcing type ventilation cannot be changed. Under the premise of the specific total capacity of ventilation air, with the continuous extension section of drivage roadway, the airflow cannot efficiently dilute gas and dust within effective range due to the wind energy losses caused by the increasing air resistance along the roadway (Whang, 1999). If the air volume increases in the process of ventilation, the energy wasting, secondary dust (Geng et al., 2018) and discomfort feelings of workers will occur. Besides, the direction angle of the outlet cannot be changed, causing the limitation of airflow path. Thus, even increasing in air volume, the gas and dust still cannot be efficiently diluted because they are accumulated in the blind ventilation zone at the heading face. Therefore, the current forcing type ventilation cannot meet the requirements for underground coal mine. In order to satisfy the actual needs under various conditions, the dynamic adaptability adjustment of airflow in the fully mechanized heading face is essential. Domestic and foreign scholars have carried out a lot of researches on distribution laws and optimization analysis in the single field, including airflow field, dust field and gas field (Li, 2016; Wang et al., 2015; Zhou et al., 2014; Luo et al., 2015; Zhang et al., 2016). However, the study on the comprehensive consideration of airflow, dust and gas field 
under the different parameters of duct outlet, including caliber, direction angle and back-forth distance, has not been proposed yet. In light of the current situation of underground coal heading face and based on analysis of the migration mechanism and distribution law of airflow, dust and gas field, the optimum migration of airflow, dust and gas field is realized by changing the parameters of outlet, which provides a theoretical basis for the safety, energy-saving and green ventilation environment in fully mechanized heading face.

\section{Materials and methods}

\section{Material}

We propose a method of the optimal adjustment for distribution of dust and gas in fully mechanized heading face. This method is applied in the Ningtiaota coal mine, which is located in Ningtiaota industrial park in Northern Shaanxi province of China in Figure 1. It is one of the four mining fields in the state's planning for the southern district of Shenfu mining, and the total output is $12.00 \mathrm{mt} / \mathrm{a}$. The forcing type ventilation is uesd in Ningtiaota mine. The air duct outlet cannot be adjusted, the path of airflow is limited, the problems of gas accumulation, dust accumulation and ventilation of dead corner in heading face should be solved.

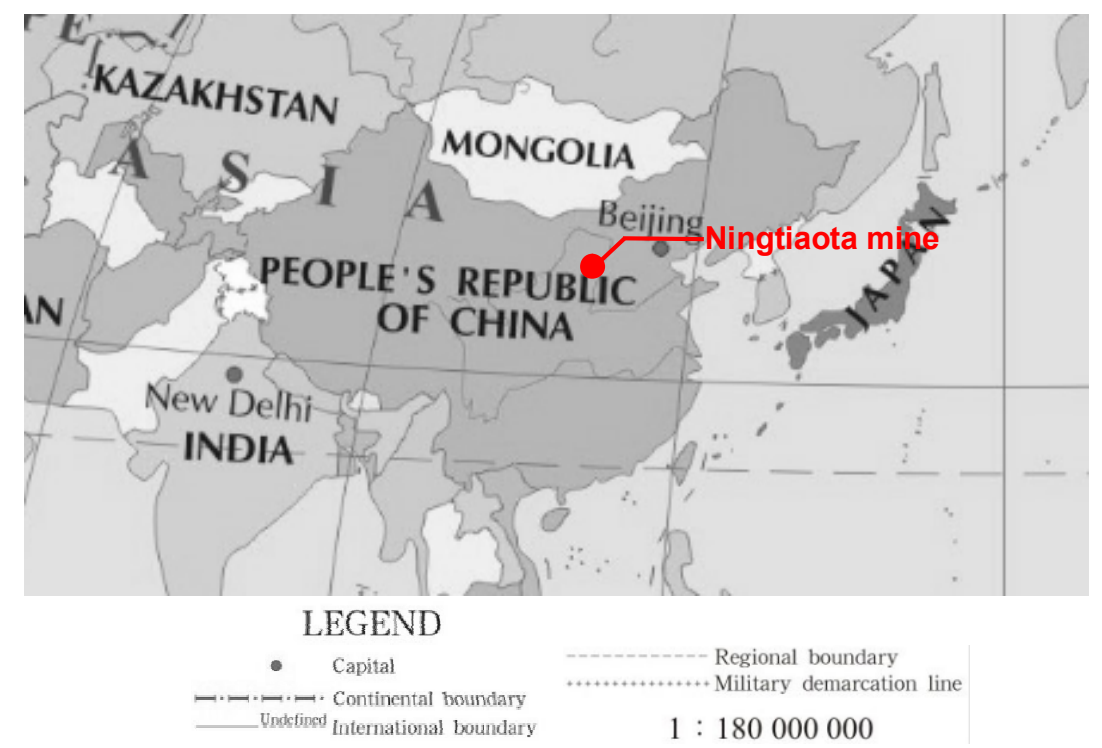

Figure 1. Location of study area in China

\section{Theoretical analysis}

\section{(1) Airflow}

Assuming no heat source in the roadway and neglecting the thermal radiation from the wall, the air flowing meets the continuity equation and the momentum conservation equation. For the flowing mode is a restricted-wall-attached jet, the airflow is turbulent, incompressible fluid, whose diffusion is a random orbit model, thus the SIMPLEC (Tang et al., 2015) algorithm and Realizable k- $\varepsilon$ turbulence model are used to control and calculate the flow field. 
k equation (Eq. 1):

$$
\frac{\partial}{\partial t}(\rho \varepsilon)+\frac{\partial}{\partial x_{i}}\left(\rho \varepsilon u_{i}\right)=\frac{\partial}{\partial x_{i}}\left(\left(u+\frac{u_{i}}{\sigma_{k}}\right) \frac{\partial k}{\partial x_{j}}\right)+G_{k}+G_{b}-\rho \varepsilon-Y_{M}+S_{k}
$$

$\varepsilon$ equation (Eq. 2):

$$
\frac{\partial}{\partial t}(\rho \varepsilon)+\frac{\partial}{\partial x_{i}}\left(\rho \varepsilon u_{i}\right)=\frac{\partial}{\partial x_{j}}\left[\left(\mu+\frac{\mu_{t}}{\sigma_{\varepsilon}}\right) \frac{\partial \varepsilon}{\partial x_{j}}\right]+\rho C_{1} S_{\varepsilon}-\rho C_{2} \frac{\varepsilon^{2}}{k+\sqrt{v \varepsilon}}+C_{1 \varepsilon} \frac{\varepsilon}{k} C_{3 \varepsilon} G_{b}+S_{\varepsilon}
$$

where $\rho\left(\mathrm{kg} / \mathrm{m}^{3}\right)$ is the density of airflow, $x_{i}, x_{j}$ coordinate element, $k(\mathrm{~J})$ is the turbulence kinetic energy, $\sigma_{k}, \sigma_{\varepsilon}$ are the prandtl number, it indicates the relationship between temperature boundary layer and flow boundary layer, $\varepsilon$ is the dissipation rating of $k, S_{\varepsilon}$ $\left(\mathrm{kg} / \mathrm{m}^{3} \mathrm{~s}\right)$ is the coupling for additional equations, $G_{k}(\mathrm{~J})$ is turbulent kinetic energy formed by average air speed, the $G_{b}(\mathrm{~J})$ is the turbulent kinetic energy formed by buoyancy, $Y_{M}$ is the affect from the expansion of turbulent motion on $\varepsilon, \mu$ is the viscosity coefficient of molecular, $\mu_{t}$ is the viscosity coefficient of turbulent, $C_{2}=1.9, C_{1 \varepsilon}=1.44$, $S_{k}, S_{\varepsilon}\left(\mathrm{kg} / \mathrm{m}^{3} \mathrm{~s}\right)$ are the source item defined by customer.

\section{(2) Gas field}

The assumptions of gas field are as follows: the same wall roughness along the roadway and the gas migration in roadway meets the species mass conservation equation, which is shown as $(E q .3)$ :

$$
\frac{\partial\left(\rho c_{s}\right)}{\partial t}+\frac{\partial\left(\rho c_{s} u\right)}{\partial x}+\frac{\partial\left(\rho c_{s} v\right)}{\partial y}+\frac{\partial\left(\rho c_{s} w\right)}{\partial z}=\frac{\partial}{\partial x}\left(D_{s} \frac{\partial\left(\rho c_{s}\right)}{\partial x}\right)+\frac{\partial}{\partial y}\left(D_{s} \frac{\partial\left(\rho c_{s}\right)}{\partial y}\right)+\frac{\partial}{\partial z}\left(D_{s} \frac{\partial\left(\rho c_{s}\right)}{\partial z}\right)+S_{s}
$$

where $\rho c_{s}\left(\mathrm{~kg} / \mathrm{m}^{3}\right)$ are the species mass conservation equation, $D_{s}$ is diffusion coefficient of components, $u, v w(\mathrm{~m} / \mathrm{s})$ is the component of velocity vector in the three directions of $x, y, z, S_{s}\left(\mathrm{~kg} / \mathrm{m}^{3} \mathrm{~s}\right)$ is the quality source item of gas component.

\section{(3) Dust field}

The dust in the heading face is a sparse phase, dust particles are a discrete phase, and air flows continuously. And the discrete phase model (DPM) of Euler-Lagrange method is used to simulate the motion of dust. The force between dust particles is neglected because the quality of particles is light, dust particle should be loaded with gravity, buoyancy pressure gradient force, etc. (Liu, 2010). Two-phase gas-solid flow mathematical model is used to analyze the migration law of dust. The mechanical model is as follows (Eqs. 4 and 5):

$$
\frac{d u_{p}}{d t}=F_{D}\left(u-u_{p}\right)+\frac{g_{x}\left(\rho_{p}-\rho\right)}{\rho_{p}}
$$




$$
F_{D}=0.75 \frac{C_{D} \rho\left|\mu_{p}-\mu\right|}{\rho_{p} d_{p}}
$$

where $F_{D}\left(u-u_{p}\right)(\mathrm{N} / \mathrm{kg})$ is the mass per unit mass drag force, $C_{D}$ is the drag coefficient, $u$ $(\mathrm{m} / \mathrm{s})$ is the air velocity of fluid phase, $u_{p}(\mathrm{~m} / \mathrm{s})$ is the particle velocity, $\mu\left(\mathrm{m}^{2} / \mathrm{s}\right)$ is the fluid viscosity, $\rho\left(\mathrm{kg} / \mathrm{m}^{3}\right)$ is the fluid density, $\rho_{p}\left(\mathrm{~kg} / \mathrm{m}^{3}\right)$ is the particle density, $d_{p}(\mathrm{~m})$ is the particle diameter.

\section{Finite element analysis method and verification}

The air duct is installed at the upper of the side of roadway wall. For ensuring the precision of model calculation, the roadheader is simplified into two parts, one is a machine part, and another is a cutting part. The end of the outlet is set as an inlet, the tail section of the roadway is set as an outlet, the outlet pressure is 0 , and there is no slip on the wall surface. In the gas field, the exposed coal wall at heading face is set as the gas emission source. In dust field, the dust source is set at the heading face. Tetrahedron method is used to mesh the geometric model, and the surface mesh unit is set as a triangle. The adjustment schematic diagram of duct outlet on the fully mechanized heading face is shown in Figure 2, and the formulas are as follows.

Hydraulic caliber (Eq. 6):

$$
d_{H}=\frac{4 A}{S}
$$

where $d_{H}(\mathrm{~m})$ is the hydraulic caliber, $A\left(\mathrm{~m}^{2}\right)$ is the fluid cross-sectional area, $S(\mathrm{~m})$ is the wetted perimeter.

Reynolds number (Eq. 7):

$$
\operatorname{Re}_{H}=\frac{\rho v d_{H}}{\mu}
$$

where $\rho\left(\mathrm{kg} / \mathrm{m}^{3}\right)$ is the air density, $v(\mathrm{~m} / \mathrm{s})$ is the speed of airflow, $\mu(\mathrm{Pa} \cdot \mathrm{S})$ is the coefficient of viscosity.

Formula turbulence intensity can be derived from Equations 8 and 9:

$$
I=0.16\left(\operatorname{Re}_{H}\right)^{-\frac{1}{8}}
$$

where $I$ is turbulence intensity, $R_{e H}$ is Reynolds number.

Gas emission source term:

$$
s_{i}=\frac{C Q \rho \varphi}{60 \mathrm{~V}}
$$

where $s_{i}\left(\mathrm{~kg} \cdot \mathrm{m}^{-1} \cdot \mathrm{s}^{-1}\right)$ is the gas emission source term, $C\left(\mathrm{~g} / \mathrm{m}^{3}\right)$ is the concentration of emission gas, $Q\left(\mathrm{~m}^{3} / \mathrm{min}\right)$ is the air volume in roadway, $\rho\left(\mathrm{kg} / \mathrm{m}^{3}\right)$ is the gas density, $V$ $\left(\mathrm{m}^{3}\right)$ is the volume of emission gas, $\varphi$ is the proportion of each gas component. 


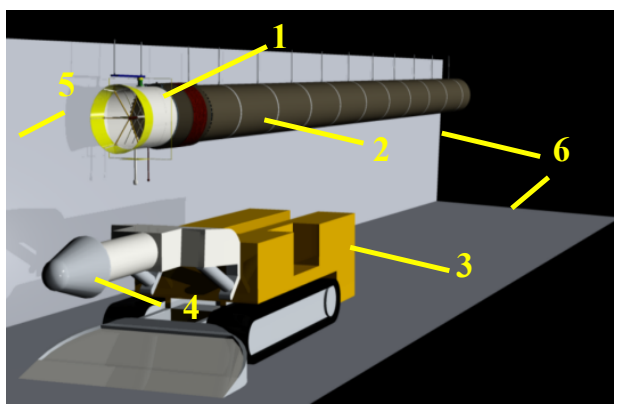

1-Adjustment device of duct outlet; 2-air duct; 3-Mian body of

Roadheader; 4-Cutting part of roadheader; 5-Tunnelling heading face; 6-Roadway

Figure 2. Schematic diagram of air outlet adjustment in the fully mechanized mining face

Taking Ningtiaota coal mine as the research object, the numerical simulation scheme is established, and the feasibility of the numerical simulation scheme is verified. The cross-section of roadway is rectangular $(6.25 \mathrm{~m} \times 3.75 \mathrm{~m})$, the airspeed at the duct outlet is $8.089 \mathrm{~m} / \mathrm{s}$, and the parameters of other boundary conditions of airflow field and gas field are set as shown in Tables 1, 2 and 3. The geometric model and finite element model of the fully mechanized heading face are shown in Figure 3.

The air velocity at the height of pedestrian breathing in the air return side at the distance of $6 \mathrm{~m}$ from outlet to heading face and the dust concentration at the distance of $8 \mathrm{~m}$ from the duct outlet to heading face are selected as measured objects, the measured points 1 as shown in Figure 4. The results of comparing the measured data and simulation data are shown in Figure 5 that indicates the distribution of airflow and dust is consistent with the actual situation, which proves the numerical simulation scheme of dust field is feasible.

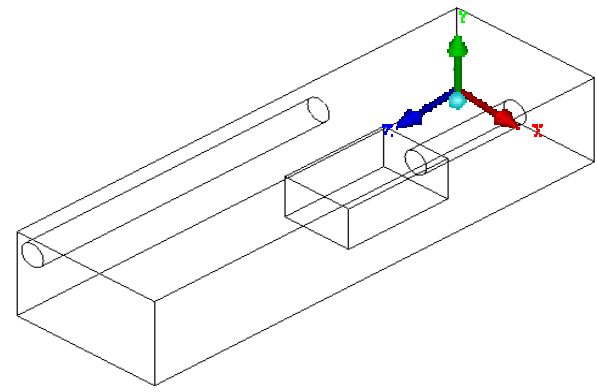

a

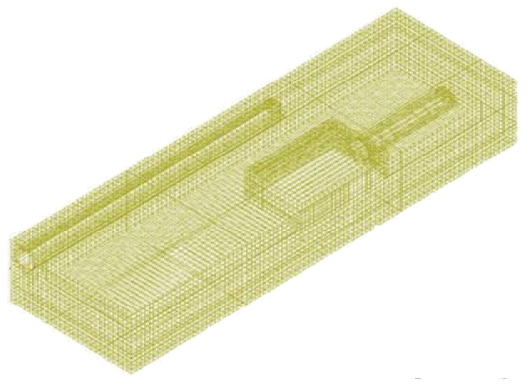

b

Figure 3. The fully mechanized heading face model. a Geometric model. $\boldsymbol{b}$ Finite element model

Table 1. Boundary condition setting of airflow field

\begin{tabular}{c|c}
\hline Condition & Define \\
\hline Air Density $\left(\mathrm{kg} / \mathrm{m}^{3}\right)$ & 1.199 \\
Air Viscosity $(\mathrm{P} \bullet \mathrm{s})$ & $1.7894 \mathrm{e}-0.5$ \\
Operating Pressure $(\mathrm{Pa})$ & 101325 \\
Hydraulic caliber $(\mathrm{m})$ & 1 \\
Turbulence Intensity $(\%)$ & 2.526 \\
\hline
\end{tabular}


Table 2. Boundary condition setting of the gas field

\begin{tabular}{|c|c|c|}
\hline Name & Material & Define \\
\hline \multirow{2}{*}{$\mathrm{CH}_{4}$} & Density $\left(\mathrm{kg} / \mathrm{m}^{3}\right)$ & 0.6679 \\
\hline & Viscosity & $1.087 \mathrm{e}-05$ \\
\hline \multirow{5}{*}{ Coal } & Density $\left(\mathrm{kg} / \mathrm{m}^{3}\right)$ & 1530 \\
\hline & Cp (Specific Heat) (j/kg-k) & 2700 \\
\hline & Thermal Conductivity (w/m-k) & 0.17 \\
\hline & Porosity of porous media & 0.2 \\
\hline & Quality source term $\left(\mathrm{kg} /\left(\mathrm{m}^{3} \cdot \mathrm{s}\right)\right)$ & 0.001 \\
\hline
\end{tabular}

Table 3. Boundary condition setting of dust field

\begin{tabular}{c|c}
\hline Material & Define \\
\hline Model & Discrete Random Walk Model \\
Minimum particle $(\mathrm{m})$ & $5 \mathrm{e}-07$ \\
Maximum particle $(\mathrm{m})$ & $2 \mathrm{e}-04$ \\
Medium particle size $(\mathrm{m})$ & $3.25 \mathrm{e}-05$ \\
Mass flow rate $\left(\mathrm{kg} \cdot \mathrm{s}^{-1}\right)$ & 0.016 \\
Particle size distribution & Rosin-Rammler \\
Particle size distribution exponential & 1.42 \\
\hline
\end{tabular}
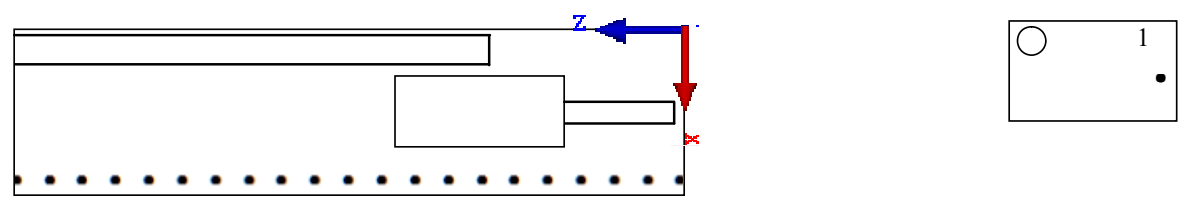

Figure 4. Distribution of measured points

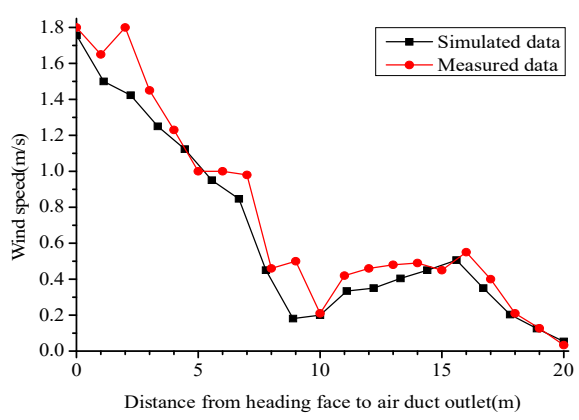

$\mathbf{a}$

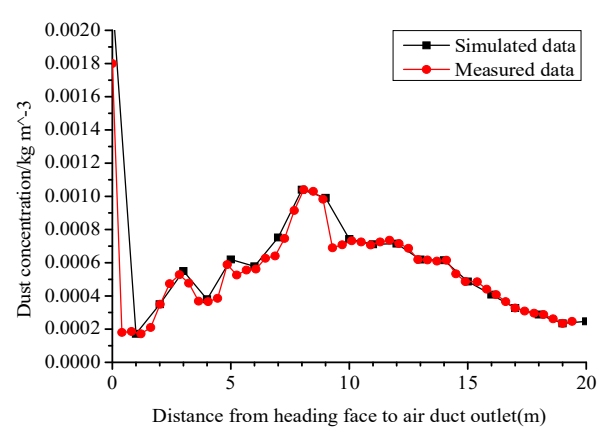

b

Figure 5. Comparing the measured data and simulation data of airflow-dust field. a Air velocity distribution at air return side. $\boldsymbol{b}$ Dust concentration distribution at air return side

According to the contour of the gas concentration of different cross-section at the distance of $6 \mathrm{~m}$ from the duct outlet to heading face (see Figure 6 ), $\mathrm{Z}=1.0$ represents 
$\mathrm{X}$-Y plans, which is $1.0 \mathrm{~m}$ away from heading face, and the direction of $\mathrm{Z}$ axis is the reverse direction of roadheader working. It is known that the gas concentration at the side of duct outlet is apparently lower than that at the air return side. According to the average values of simulation, the gas concentration at the cross section of $Z=0.2 \mathrm{~m}$ and $\mathrm{Z}=1 \mathrm{~m}$ are $0.186 \%$ and $0.147 \%$, which is consistent with the measured values of $0.187 \%$ and $0.146 \%$, respectively, verifying the numerical simulation scheme of gas field is feasible.
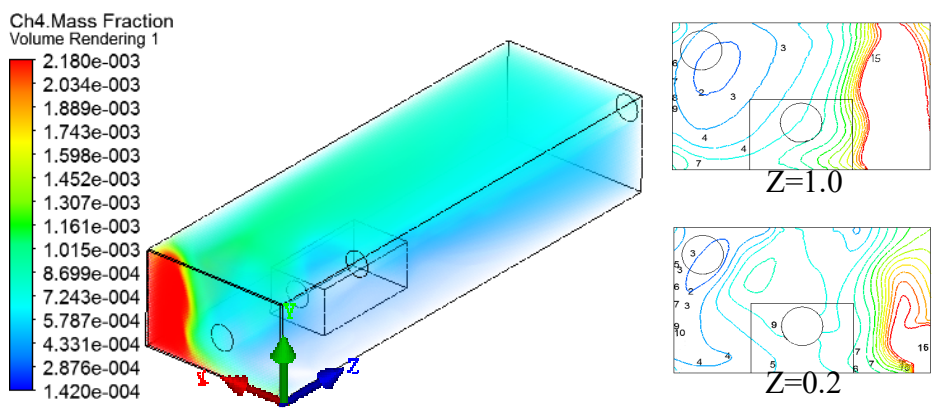

Figure 6. Contour map of gas concentration at roadway cross section

\section{Migration mechanism and existing problems in airflow dust and gas field}

Migration mechanism and existing problems in airflow field

According to the definition of hydrodynamic, it is known that the airflow at the duct outlet is restricted attachment jet-flow under the forcing type ventilation (Wang et al., 2004), and the jet-flow zone is in front of duct outlet (see Figure 7).

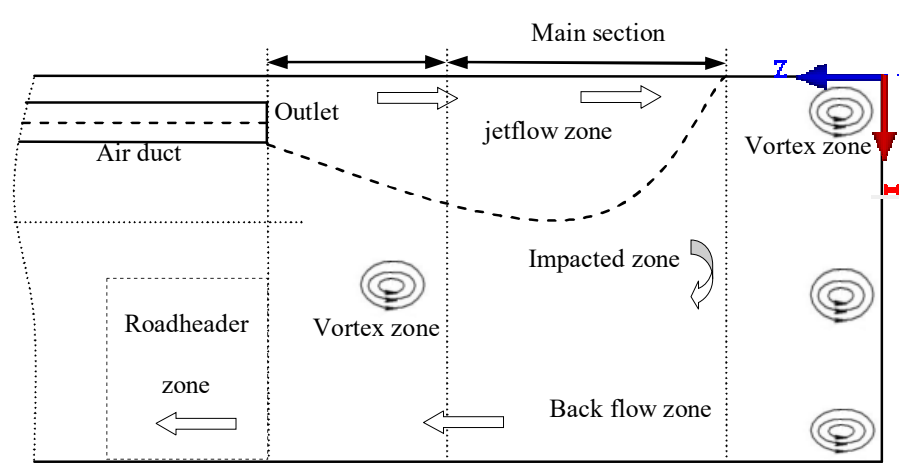

Figure 7. Schematic diagram of air flow structure in the fully mechanized heading face

In the process, the airflow will continuously absorb air surrounding, resulting in energy loss. Then with the jet expanding continually, the airspeed at the axis of outlet is equal to the initial velocity at the outlet and keeps constant, which is the start section of jetflow. Then the speed begins to decrease to 0 , which stage is the main section, the effective range of the jet-flow includes the start section and the main section. With the increasing distance from the outlet to the heading face, the effective range is reduced by the resistant force along the roadway. The air-flowing is attached to the wall and limited by roadway boundary, leading to the backflow formed at the bottom of roadway. The dust and gas will be brought out utilizing the backflow. However, the airspeed at return 
side is low, which has a slight influence on the air disturbance at the upper and lower corners of the air-return side where the original air keeps relatively stable state. When the boundary layer of original air is loaded by tangential friction force or disturbed by air, the vortex is formed. Similarly, the jet-flow boundary layer disturbs air at the rear of roadheader where the vortex is formed, and the airflow of normal migration is affected and the vortex formed in front of the heading machine for the large volume of roadheader.

According to the literature (Zan et al., 2010), the motion parameters of restricted attachment jet-flow are related to restriction degree $n$, the calculation formula of jet restriction degree is as follows (Eq. 10):

$$
n=\frac{A_{0}}{A}
$$

where $A_{0}\left(\mathrm{~m}^{2}\right)$ is the section area of the outlet, $A\left(\mathrm{~m}^{2}\right)$ is the section area of roadway.

From the formula above, the smaller restriction degree $\mathrm{n}$ is, the stronger the characteristics of the free-wall-attached jet will be, whereas the restricted-wall-attached jet characteristics become weaker.

The distribution regularity of airflow field, gas field and dust field are simulated at distances of 5, 6, 7, 8, 9 and $10 \mathrm{~m}$, respectively, from the duct outlet to the heading face, then the existing problems of original field are obtained.

Turbulence is the main factor for gas dust diffusion, and vortex should be emphasized (Gong et al., 2017a). To analyze clearly the airflow distribution law at workers' activity district and ensure the position of turbulence, the airflow distribution under different distances from the outlet to heading face is shown in Figure 8, the specific results of air distribution shown in Table 4.

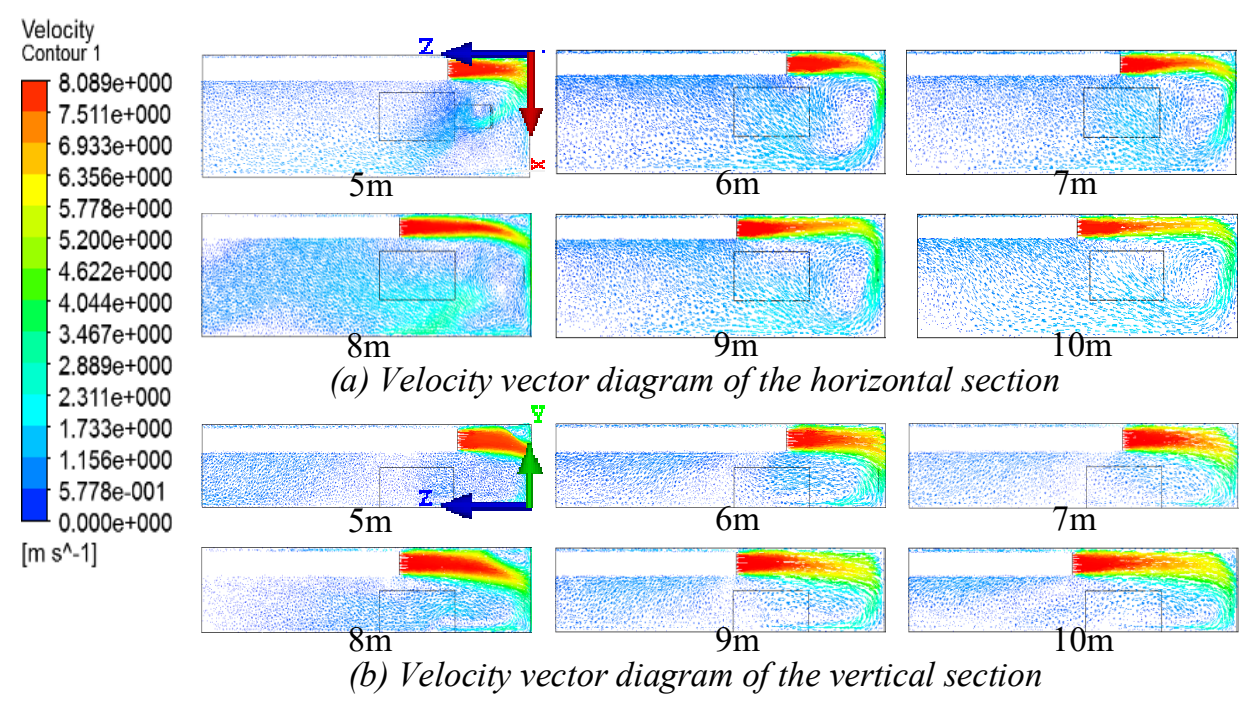

Figure 8. Airflow distribution under different distance from outlet to heading face

The simulation results show that when the duct outlet is close to the heading face $(5 \mathrm{~m})$, the driver will feel extremely uncomfortable because of overhigh velocity of 
airflow. The vortex formed above the roadheader, when the airflow impacts the heading face and destroys air return zone, which causes dust accumulation and environment pollution. Expanding outlet can decrease airspeed and shorten the effective range of jetflow to make sure the back-flow district formed at the heading face, which is conducive to bringing gas and dust out effectively. Whereas, when the duct outlet is far away from the heading face $(9-10 \mathrm{~m})$, the irregularly circulated motion of gas and dust occurs for the vortex formed in the front of roadheader. At the same time, the jet zone becomes longer, but the effective range will be reduced by resistance along the roadway, leading to the low air velocity when it arrives in the heading face, and resulting in the dust and gas at the producing source are difficultly diluted. Consequently, the caliber and the distance from outlet to heading face should be in a reasonable range.

Table 4. Airflow field distribution

\begin{tabular}{|c|c|c|c|}
\hline $\begin{array}{c}\text { Distance } \\
\text { from heading } \\
\text { face }(\mathrm{m}) \\
\end{array}$ & $\begin{array}{c}\begin{array}{c}\text { Air velocity at } \\
\text { diver place } \\
(\mathbf{m} / \mathbf{s})\end{array} \\
\end{array}$ & $\begin{array}{c}\text { Air velocity at } \\
\text { walking place } \\
(\mathrm{m} / \mathrm{s})\end{array}$ & Turbulence formed position \\
\hline 5 & $0.3 \sim 1.4$ & $0.2 \sim 4.7$ & The end of the jet-flow \\
\hline 6 & $0.28 \sim 3.0$ & $0.27 \sim 2.9$ & In front of roadheader \\
\hline 7 & $0.3 \sim 2.8$ & $0.25 \sim 3.0$ & The right side of roadheader \\
\hline 8 & $0.25 \sim 0.8$ & $0.22 \sim 0.75$ & Above the jet flow zone and the right side of roadheader \\
\hline 9 & $0.1 \sim 0.8$ & $0.23 \sim 0.8$ & The right side and in front of roadheader \\
\hline 10 & $0.1 \sim 0.9$ & $0.2 \sim 1.7$ & In front of roadheader \\
\hline
\end{tabular}

\section{Migration mechanism and existing problems in gas field}

The wall is a porous medium in roadway, and gas flows out from heading face, gas molecules are irregularly moved from high to low concentration. The gas is mainly produced from heading face, its density is lighter than that of air and easily accumulated on the roof. The gas at the upper corner will be disturbed by airflow, then vortex formed. However, the wind intensity at the lower corner is weak, so that its disturbance to the gas is light, resulting in the gas concentration at lower corner is higher than that at upper corner. The gas in the air-return area is brought out, because vortex formed near the roadheader.

The method of gas diluting is to blow fresh air to the heading face. We proposes the gas in the ventilation dead corner of roadway should be diluted by changing the caliber, direction angle and distances from the heading face, then the air volume be controlled at heading face.

The explosion would most likely occur due to the high gas concentration. The gas concentration distribution at different distances from the duct outlet to the heading face are numerically simulated, and the reasons of gas accumulation are investigated. Aimed at revealing the gas field distribution, we obtained the gas concentration distribution at the closest distance $(5 \mathrm{~m})$, middle distance $(7 \mathrm{~m})$ and the farthest distance $(10 \mathrm{~m})$ as shown in Figure 9.

The simulation results show that: with the increase of distance from the heading face, the gas concentration increases, but the average gas concentration gets lower. It is mainly accumulated in the upper and lower corner of the air return side, and the gas is difficult to be brought out because the airflow is weak in the lower position. The gas 
concentration tends to be stable as the distance further away from the heading face. When the duct outlet is $5 \mathrm{~m}$ away from the heading face, the airflow impacts the heading face, and the ventilation return path cannot be formed, resulting in the gas diffussion thus it is difficult for gas to be efficiently moved out. When duct outlet is $6 \mathrm{~m}$ from the heading face, compared with the gas concentration at the backflow side, it is lower in the jet flow zone. When the distance from duct outlet to heading face is 7-8 $\mathrm{m}$, the jet flow disturbs the air, and gas is well diluted. When the duct outlet is $9-10 \mathrm{~m}$ from the heading face, the jet flow will be affected by resistance in the roadway, causing the effective range becomes shorter and severe gas accumulation takes place at the heading face. Based on the analysis above, we should focus on optimizing the gas field at specific distances of 5-10 m between duct outlet and heading face.
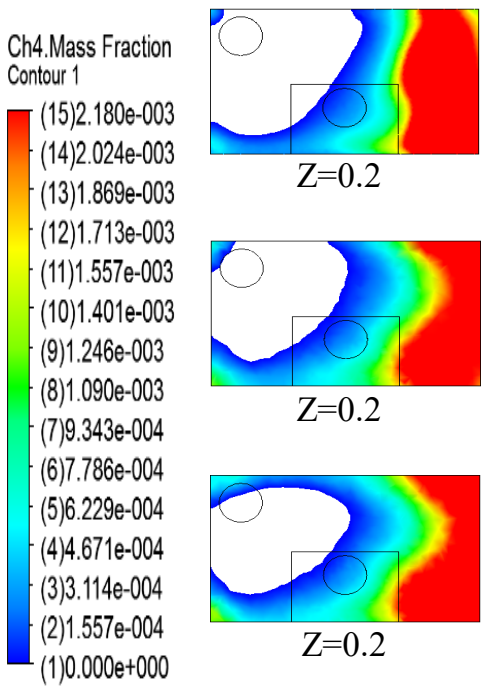

$\mathrm{Z}=0.2$

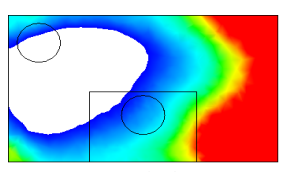

$\mathrm{Z}=0.2$

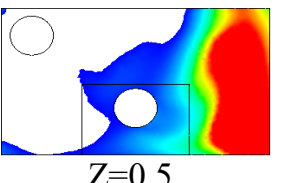

(a) From outlet

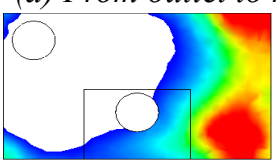

$\mathrm{Z}=0.5$

(b) From outlet to heading face is $7 \mathrm{~m}$

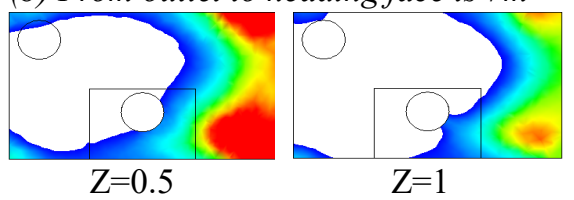

(c) From outlet to heading face is $10 \mathrm{~m}$
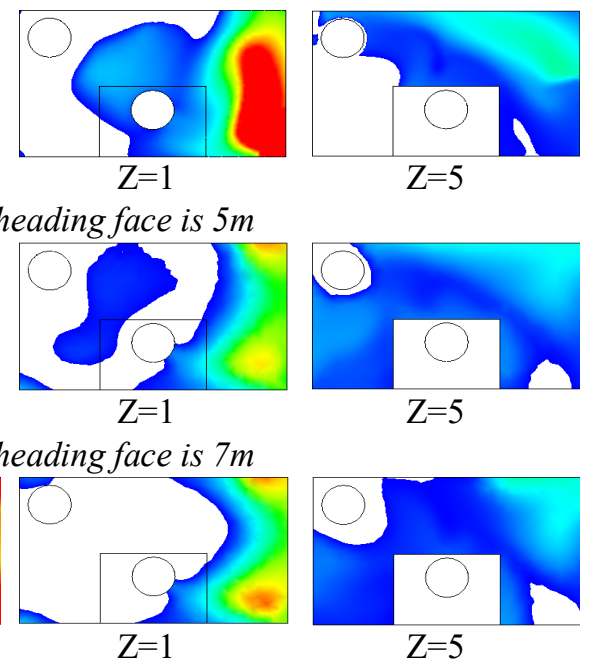

Figure 9. Contour of gas concentration in different cross-section of roadway

\section{Migration mechanism and existing problems in dust field}

The jet flow zone is generated by the directly impact of airflow from the outlet, which can effectively disperse dust. The dust concentration is lower than that in the vortex zone. At the same time, the jet absorbs the dust in the surrounding air, the absorbed dust will be taken to the heading face, resulting in high dust concentration. The vortex formed at the front of roadheader, causing the dust diffusion in the roadway and difficultly settle down. Under the forced type ventilation, the air velocity is low at the back of roadheader. The respirable dust tends to move toward the backflow side, where the small particle dust accumulates mainly at the upper corner (Alam, 2006; Candra et al., 2014), thus the dust concentration in the backflow zone is higher than that in the jet zone (Gong et al., 2017b).

To better describe the distribution of dust concentration in each zone, calculation models in each zone were established (Liu et al., 2002), and the equations are as follows (Eq. 11, 12 and 13):

$$
\bar{C}_{a}=C_{0}+\frac{G Q^{\prime}}{Q_{0}\left(Q_{0}+Q^{\prime}\right)}
$$




$$
\begin{aligned}
& \bar{C}_{b}=C_{0}+\frac{G}{Q_{0}} \\
& \bar{C}_{c}=C_{0}+\frac{G}{Q_{0}}
\end{aligned}
$$

Where, $\mathrm{C}_{\mathrm{a}}\left(\mathrm{mg} / \mathrm{m}^{3}\right)$ is dust concentration in jet-flow zone,, $\mathrm{C}_{\mathrm{b}}\left(\mathrm{mg} / \mathrm{m}^{3}\right)$ is dust concentration in vortex zone,, $\mathrm{C}_{\mathrm{c}}\left(\mathrm{mg} / \mathrm{m}^{3}\right)$ is dust concentration in backflow zone, $\mathrm{C}_{0}$ $\left(\mathrm{mg} / \mathrm{m}^{3}\right)$ is dust concentration in air-flow, $\mathrm{Q}_{0}\left(\mathrm{mg} / \mathrm{m}^{3}\right)$ is forced air volume, $\mathrm{Q}_{1}\left(\mathrm{mg} / \mathrm{m}^{3}\right)$ is air volume discharged from heading face, $Q^{\prime}\left(\mathrm{mg} / \mathrm{m}^{3}\right)$ is suction volume in jet-flow, $\mathrm{G}$ $\left(\mathrm{mg} / \mathrm{m}^{3}\right)$ is dust intensity.

According to the formula analysis, it is concluded that the dust concentration in the jet area, vortex area and backflow area are positively correlated with the dust intensity, and negatively correlated with forced air volume. And under the premise of the reasonable distribution of the airflow field, the larger the air volume is, the better effect of the dust dilution will be.

Considering that dust concentration is the main cause of pneumoconiosis and environmental pollution, the numerical simulations of dust field at different distances from the outlet to heading face are carried out, and the dust concentration at the different cross-sections of roadway are shown in Figure 10.

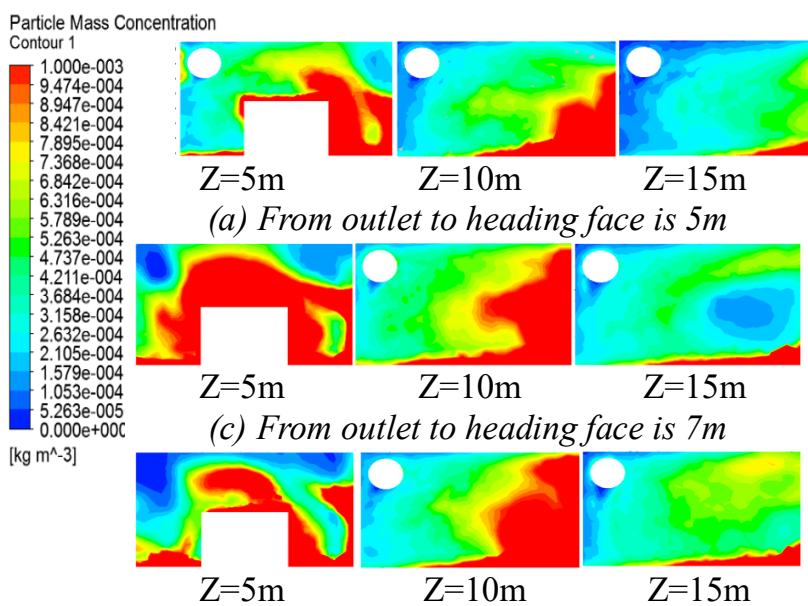

(e) From outlet to heading face is $9 m$

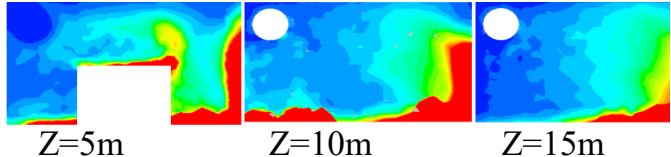

(b) From outlet to heading face is $6 \mathrm{~m}$

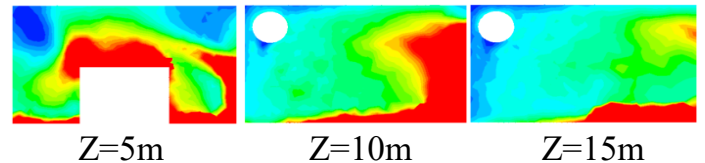

(d) From outlet to heading face is $8 m$

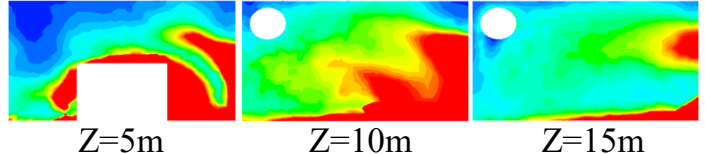

(f) From outlet to heading face is $10 \mathrm{~m}$

Figure 10. Dust concentration distribution at different distances from air outlet to heading face

As can be seen from Figure 10, the dust concentration on the return side wall and the air duct side gradually decreases as the distance from the outlet to the heading face increasing. According to the actual working environment, the range of $5-10 \mathrm{~m}$ is working positions for drivers, and within this range, affected by the roadheader, vortex is formed and dust accumulated, which obstruct the driver's vision. When the distance from the outlet to heading face is 5-6 m, the dust concentration is low in driver's position and heading face. When the distance is $7-10 \mathrm{~m}$, the dust concentration increases in backflow, which is not conducive to safe production. The specific location of dust accumulation is shown in Table 5. 
Table 5. Distribution of dust-flowing field

\begin{tabular}{c|c|c|c}
\hline $\begin{array}{c}\text { Distance from } \\
\text { heading face }\end{array}$ & $\begin{array}{c}\text { Dust concentration at } \\
\text { the range of driver } \\
\text { activity area }\left(\mathbf{k g} / \mathbf{m}^{3}\right)\end{array}$ & $\begin{array}{c}\text { Dust concentration at } \\
\text { backflow side }\left(\mathbf{k g} / \mathbf{m}^{3}\right)\end{array}$ & The position of dust accumulation \\
\hline $5 \mathrm{~m}$ & $1.0 \times 10^{-3} \sim 5.0 \times 10^{-3}$ & $3.2 \times 10^{-5} \sim 1.4 \times 10^{-3}$ & Front, right and above of roadheader \\
$6 \mathrm{~m}$ & $2.4 \times 10^{-4} \sim 1.0 \times 10^{-3}$ & $2.4 \times 10^{-5} \sim 4.0 \times 10^{-4}$ & Wall at backflow along roadway \\
$7 \mathrm{~m}$ & $1.0 \times 10^{-3} \sim 5.0 \times 10^{-3}$ & $2.5 \times 10^{-5} \sim 1.6 \times 10^{-3}$ & Front of roadheader \\
$8 \mathrm{~m}$ & $5.1 \times 10^{-4} \sim 8.0 \times 10^{-3}$ & $2.6 \times 10^{-5} \sim 1.1 \times 10^{-3}$ & Above and right of roadheader \\
$9 \mathrm{~m}$ & $9.0 \times 10^{-4} \sim 7.8 \times 10^{-3}$ & $6.6 \times 10^{-5} \sim 1.5 \times 10^{-3}$ & Back of roadheader \\
$10 \mathrm{~m}$ & $7.6 \times 10^{4} \sim 8.0 \times 10^{-3}$ & $1.2 \times 10^{-5} \sim 2.3 \times 10^{-3}$ & Driver position \\
\hline
\end{tabular}

\section{Results}

\section{Influence of air outlet caliber change on airflow dust and gas distribution}

To improve the utilization rate of underground energy, under the premise of constant air volume, we propose that the outlet caliber should be adjustable for changing the airflow speed. According to the migration mechanism of the airflow dust and gas, reasonable airflow distributions will have a direct influence on the gas and dust distribution in heading face. The distribution of airflow field at calibers of $0.7,0.8,0.9$, $1.0,1.1$ and $1.2 \mathrm{~m}$ are numerically simulated, respectively. The velocity distribution of airflow field at the horizontal plane is shown in Figure 11.
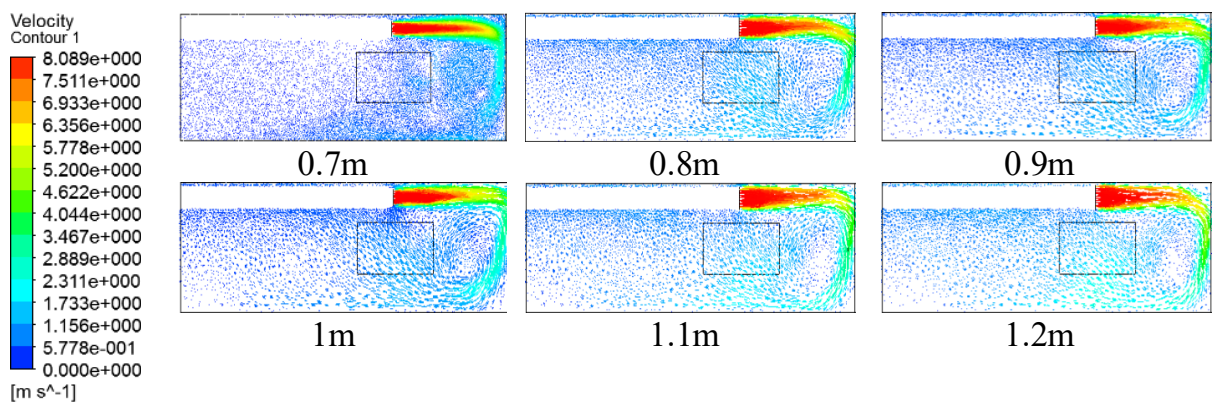

Figure 11. Airflow velocity distribution under different caliber

As the caliber increases, the effective range of jet becomes short, and the airspeed at the heading face decreases. The vortex is formed at front of roadheader and is beneficial to diluting the dust and gas at the heading face; and the larger the caliber of the air outlet, the larger radius of curvature of backflow is. Under the premise of the certain total air volume, when the outlet is far away from the heading face, the axial velocity of jet can be increased by caliber necking; and when the outlet is close to the heading face, the air velocity is decreased by reducing the impact force on the heading face. In summary, the adjustment methods of outlet caliber are put forward to meet the Coal Mine Safety Regulations on the air velocity ranging of $0.25-4 \mathrm{~m} / \mathrm{s}$. When the distance from the outlet to the heading face is $5 \mathrm{~m}$, the caliber should be extended to 1.1 and 1.2 $\mathrm{m}$; when the distance is $6-8 \mathrm{~m}$, the caliber's unchanged (at $1 \mathrm{~m}$ ), and it is necked to 0.8 and $0.9 \mathrm{~m}$ when the distance is $9-10 \mathrm{~m}$. At distances of $5 \mathrm{~m}$ and $10 \mathrm{~m}$, the distribution of the airflow dust and gas field under different caliber are shown in Figures 12 and 13. 
The different value of $\mathrm{Y}$ in Figures $12 a$ and $13 a$ mean different $\mathrm{X}-\mathrm{Z}$ plans, for example, $\mathrm{Y}=1.0 \mathrm{~m}$ indicates the $\mathrm{X}-\mathrm{Z}$ plan, which is $1.0 \mathrm{~m}$ away from ground.

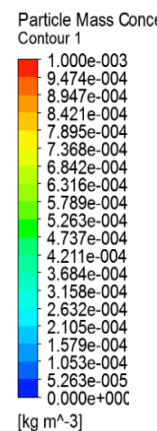

$$
\begin{array}{r}
1.452 \mathrm{e}-003 \\
-1.307 \mathrm{e}-003 \\
-1.162 \mathrm{e}-003 \\
-1.016 \mathrm{e}-003 \\
-8.712 \mathrm{e}-004 \\
-7.260 \mathrm{e}-004 \\
-5.808 \mathrm{e}-004 \\
-4.356 \mathrm{e}-004 \\
2.904 \mathrm{e}-004 \\
1.452 \mathrm{e}-004 \\
0.000 \mathrm{e}+000
\end{array}
$$$$
\begin{aligned}
& \text { Ch4.Mass Fraction } \\
& \text { Contour } 1
\end{aligned}
$$
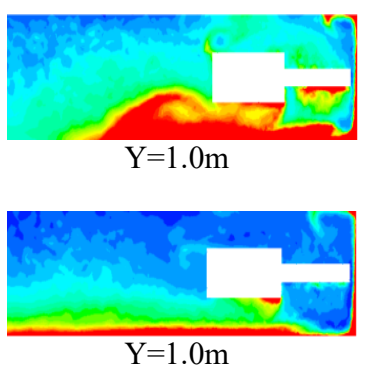

Caliber is $1.2 \mathrm{~m}$
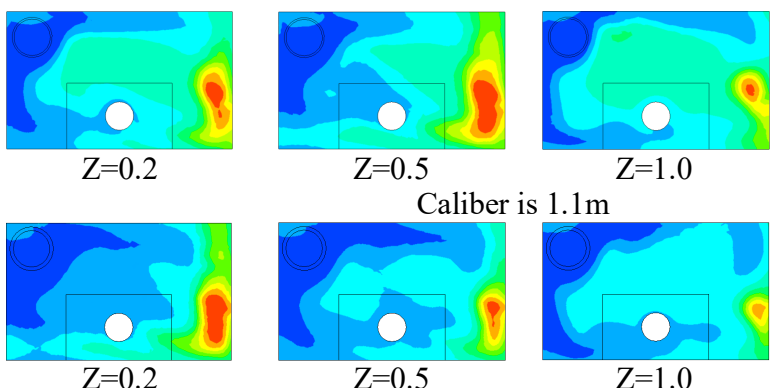

Caliber is $1.1 \mathrm{~m}$
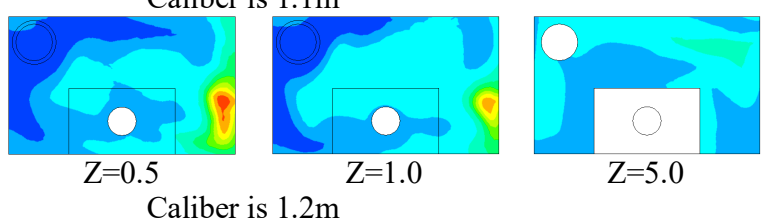

$Z=5.0$

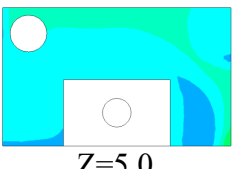

$\mathrm{Z}=5.0$

(b) Gas concentration distribution at different cross-section

Figure 12. Dust and gas concentration distribution under different caliber of outlet at the distance of $5 \mathrm{~m}$ from heading face

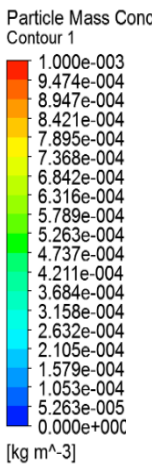

Ch4.Mass Fraction
Contour 1
\begin{tabular}{|l|l}
$1.000 \mathrm{e}-003$ \\
$-9.000 \mathrm{e}-004$ \\
$8.000 \mathrm{e}-004$ \\
$7.000 \mathrm{e}-004$ \\
$6.000 \mathrm{e}-004$ \\
$5.000 \mathrm{e}-004$ \\
$4.000 \mathrm{e}-004$ \\
$3.000 \mathrm{e}-004$ \\
$2.000 \mathrm{e}-004$ \\
$1.000 \mathrm{e}-004$ \\
$0.000 \mathrm{e}+000$
\end{tabular}

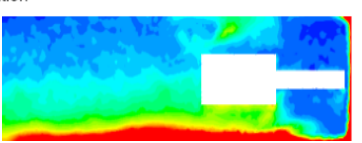

$\mathrm{Y}=1.0 \mathrm{~m}$

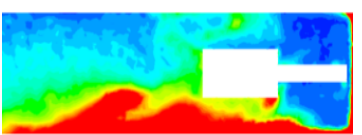

$\mathrm{Y}=1.0 \mathrm{~m}$

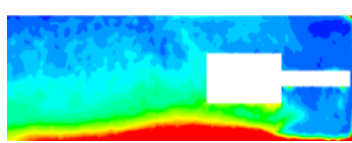

$\mathrm{Y}=1.5 \mathrm{~m}$

Caliber is $0.8 \mathrm{~m}$

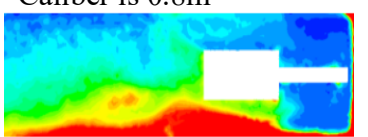

$\mathrm{Y}=1.5 \mathrm{~m}$

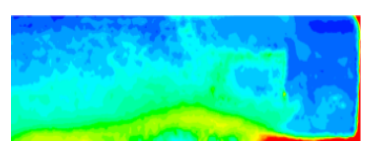

$\mathrm{Y}=2.0 \mathrm{~m}$

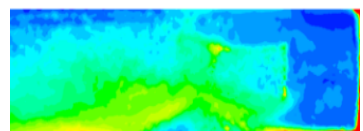

$\mathrm{Y}=2.0 \mathrm{~m}$

Caliber is $0.9 \mathrm{~m}$

(a) Dust concentration distribution at different horizontal section

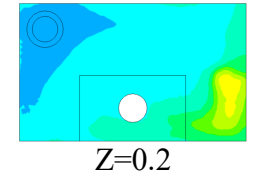

$\mathrm{Z}=0.2$

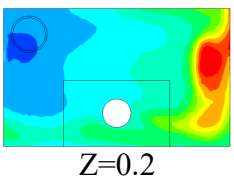

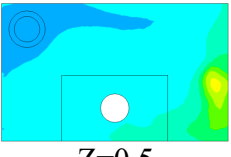

$\mathrm{Z}=0.5$

Caliber is $0.8 \mathrm{~m}$

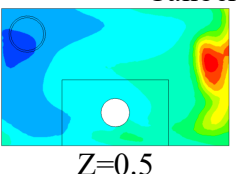

Caliber is $0.9 \mathrm{~m}$

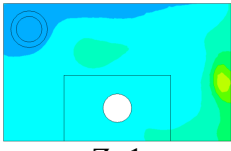

$\mathrm{Z}=1$

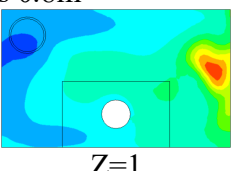

$\mathrm{Z}=1$

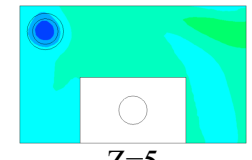

$\mathrm{Z}=5$

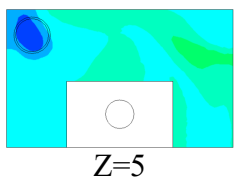

$\mathrm{Z}=5$

(b) Gas concentration distribution at different horizontal section

Figure 13. Dust and gas concentration distribution under different caliber of outlet at the distance of $10 \mathrm{~m}$ from heading face 
At the distance of $5 \mathrm{~m}$, extending caliber can effectively decrease the dust and gas concentration (see Figure 12). When the caliber is $1.1 \mathrm{~m}$, dust is accumulated above the heading face, which will seriously pollute the working environment of driver, and the gas concentration at the air return side is a tendency of decreasing-increasingdecreasing. When the caliber is $1.2 \mathrm{~m}$, the dust concentration is low with uniform distributions, the orange area gradually gets shrunk, indicating that gas concentration decreases. At the distance of $10 \mathrm{~m}$, the necked caliber can effectively improve the distribution of the dust and gas field (see Figure 13). When the caliber is $0.8 \mathrm{~m}$, the orange area representing the dust and gas accumulation at air return side is smaller than that of $0.9 \mathrm{~m}$ of caliber. According to the above analysis, the reasonable range of caliber is: at the distance of $5 \mathrm{~m}$, select $1.2 \mathrm{~m}$ of caliber; at distances of 6-8 m, select 1 $\mathrm{m}$ of caliber, when it is $9-10 \mathrm{~m}$, select $0.8 \mathrm{~m}$ of caliber.

\section{Influence of air outlet angle direction change on air-flow dust and gas distribution}

Due to the limitation of the geometric size of the roadway section and the premise of normal operation of roadheader, according to the existing problems in the airflow field, dust field and gas field, the velocity in backflow should be improved to break the vortex around the roadheader and dilute the dust and gas at the heading face and dead corner area. The angle of outlet should be adjusted at the horizontal right deviation of $5^{\circ}-25^{\circ}$ and vertical upward deflection of $2^{\circ}-8^{\circ}$. Selecting the angle of horizontal right deviation at $5^{\circ}, 10^{\circ}, 15^{\circ}, 20^{\circ}$ and $25^{\circ}$ and vertical upward deflection of $2^{\circ}, 4^{\circ}, 6^{\circ}$ and $8^{\circ}$; respectively, the numerical simulation experiments were carried out on the distribution of the air, dust and gas in fully mechanized heading face. Figure 14 only shows the numerical simulation results of airflow velocity distribution, gas concentration distribution and dust concentration distribution under different outlet angles when the outlet is $5 \mathrm{~m}$ away from the heading face owing to the space constraints.

The numerical simulation results show that the problems of low velocity, dead corner of ventilation and vortex area in the local area of original field can be improved by changing the angle of outlet. Under the premise of constant caliber, the angle adjustment can improve the airflow distribution near the roadheader, but it still impacts the heading face, indicating that the velocity of outlet is too high. Therefore, the velocity of outlet should be decreased by changing the caliber. Considering the reasonable distribution of the airflow gas and dust, the reasonable range of outlet angle should be in the horizontal right-skew of $5^{\circ}-15^{\circ}$ and vertical up-skew of $2^{\circ}-6^{\circ}$. To realize comprehensive optimization for the airflow field, dust field and gas field at the fully mechanize heading face, it is necessary to determine the specific angle parameter value of outlet.
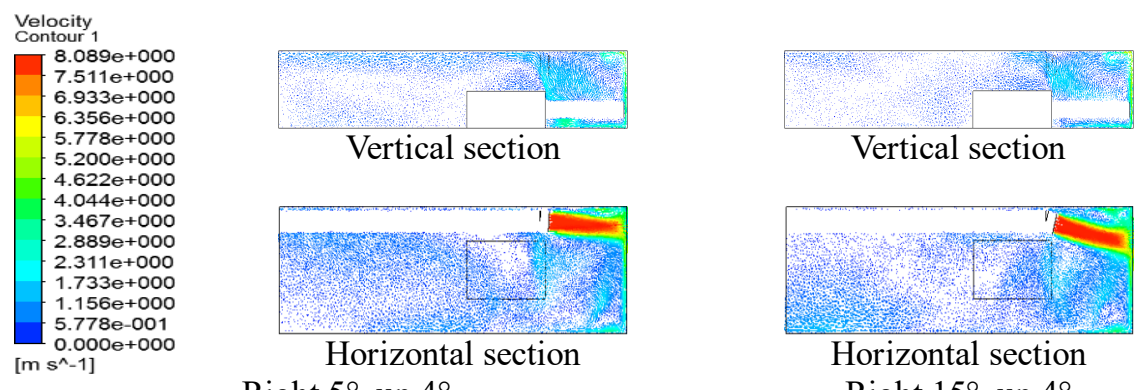

Vertical section Right $5^{\circ}$, up $4^{\circ}$

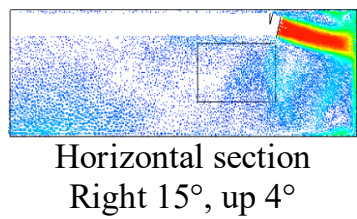

(a) Airflow velocity distribution 

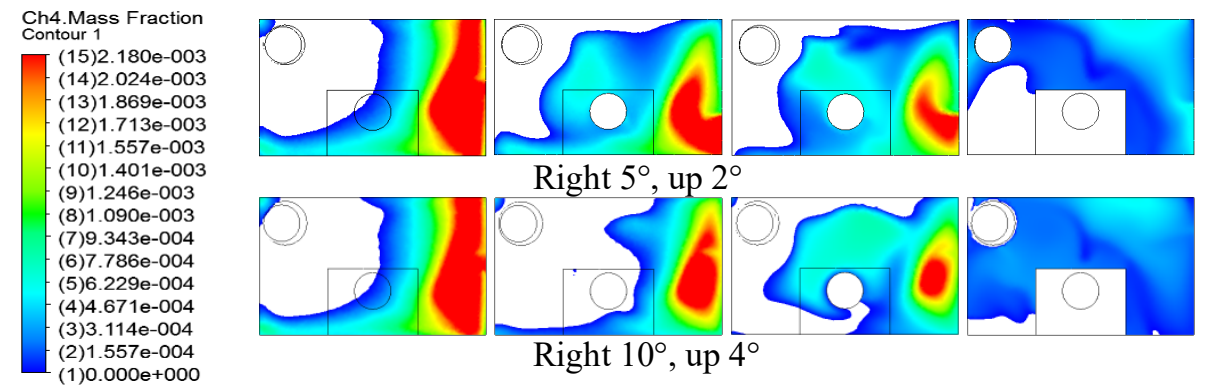

(b) Gas concentration distribution at different cross-section of heading face
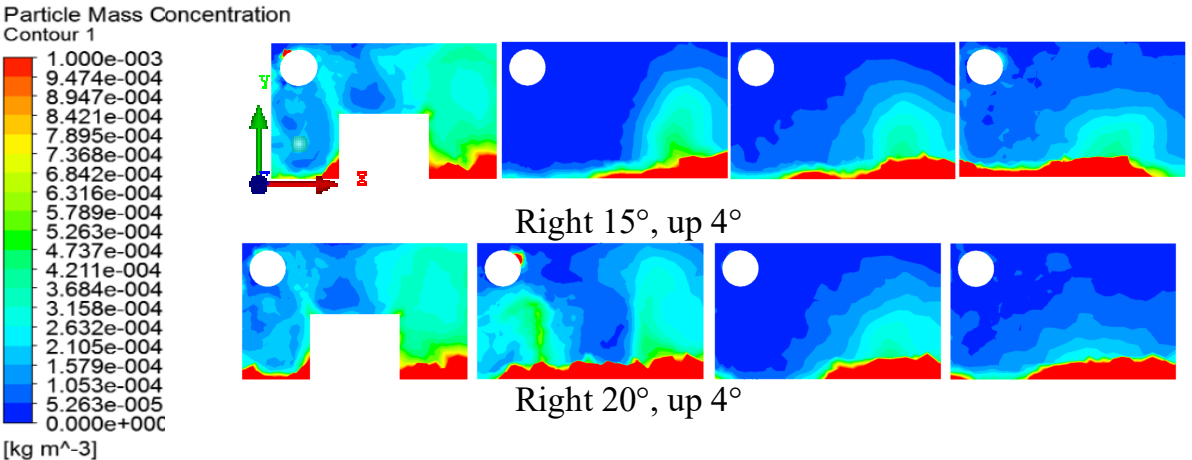

Right $15^{\circ}$, up $4^{\circ}$
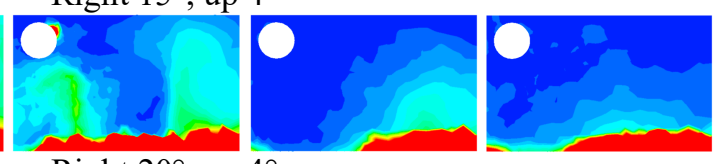

Right $20^{\circ}$, up $4^{\circ}$

(c) Dust concentration distribution at the position of the driver

Figure 14. Airflow dust and gas distribution under different angle direction of the outlet at the distance of $5 \mathrm{~m}$ from heading face

\section{Airflow adaptability adjustment for dust and gas}

\section{Design of comprehensive optimization scheme}

In light of the existing problems of the airflow field, dust field and gas field, combined with the reasonable value range of outlet parameters, we put forward a comprehensive optimization adjustment scheme for the airflow field, dust field and gas field under different distances $(5,6,7,8,9$, and $10 \mathrm{~m}$ ) from outlet to heading face (see Table 6).

Table 6. Design of optimization adjustment scheme

\begin{tabular}{|c|c|c|c|c|c|c|}
\hline Scheme & $5 \mathrm{~m}$ & $6 \mathrm{~m}$ & $7 m$ & $8 m$ & $9 m$ & $10 \mathrm{~m}$ \\
\hline Scheme 1 & $\begin{array}{l}\text { Caliber } 1.2 \mathrm{~m} \text {, } \\
\text { right } 5 \text {, up } 4\end{array}$ & $\begin{array}{l}\text { Caliber } 1 \mathrm{~m} \text {, } \\
\text { right } 5^{\circ} \text {, up } 2^{\circ}\end{array}$ & $\begin{array}{l}\text { Caliber } 1 \mathrm{~m}, \\
\text { right } 5^{\circ} \text {, up } 2^{\circ}\end{array}$ & $\begin{array}{l}\text { Caliber } 1 \mathrm{~m}, \\
\text { right } 5^{\circ} \text {, up } 2^{\circ}\end{array}$ & $\begin{array}{l}\text { Caliber } 0.8 \mathrm{~m}, \\
\text { right } 5^{\circ} \text {, up } 4^{\circ}\end{array}$ & $\begin{array}{l}\text { Caliber } 0.8 \mathrm{~m} \text {, } \\
\text { right } 5^{\circ} \text {, up } 4^{\circ}\end{array}$ \\
\hline Sch & $\begin{array}{l}\text { Caliber } 1.2 \mathrm{~m} \text {, } \\
\text { right } 15 \text {, up } 4^{\circ}\end{array}$ & $\begin{array}{c}\text { Caliber } 1 \mathrm{~m}, \\
\text { right } 10^{\circ} \text {, up } 2^{\circ}\end{array}$ & $\begin{array}{c}\text { Caliber } 1 \mathrm{~m}, \\
\text { right } 10^{\circ} \text {, up } 2^{\circ}\end{array}$ & $\begin{array}{c}\text { Caliber } 1 \mathrm{~m} \text {, } \\
\text { right } 10^{\circ} \text {, up } 2^{\circ}\end{array}$ & $\begin{array}{c}\text { Caliber } 0.8 \mathrm{~m}, \\
\text { right } 10^{\circ} \text {, up } 6^{\circ}\end{array}$ & $\begin{array}{l}\text { Caliber } 0.8 \mathrm{~m} \text {, } \\
\text { right } 10^{\circ} \text {, up } 4^{\circ}\end{array}$ \\
\hline Scheme 3 & $\begin{array}{l}\text { Caliber } 1.2 \mathrm{~m}, \\
\text { right } 15^{\circ} \text {, up } 6^{\circ}\end{array}$ & $\begin{array}{l}\text { Caliber } 1 \mathrm{~m}, \\
\text { right } 15^{\circ} \text {, up } 2^{\circ}\end{array}$ & $\begin{array}{l}\text { Caliber } 1 \mathrm{~m}, \\
\text { right } 15^{\circ} \text {, up } 2^{\circ}\end{array}$ & $\begin{array}{l}\text { Caliber } 1 \mathrm{~m}, \\
\text { right } 15^{\circ} \text {, up } 2^{\circ}\end{array}$ & $\begin{array}{c}\text { Caliber } 0.8 \mathrm{~m}, \\
\text { right } 15^{\circ}, \text { up } 2^{\circ}\end{array}$ & $\begin{array}{l}\text { Caliber } 0.8 \mathrm{~m}, \\
\text { right } 15^{\circ} \text {, up } 2^{\circ}\end{array}$ \\
\hline
\end{tabular}

\section{Discussion}

The comprehensive optimization results of the airflow, dust and gas under different adjustment schemes are compared and analyzed. The air velocity and the concentration distribution of dust and gas in backflow side at the distance of $5 \mathrm{~m}$ are shown in 
Figure 15. The optimization result of dust particle size distribution was shown in Figure 16.

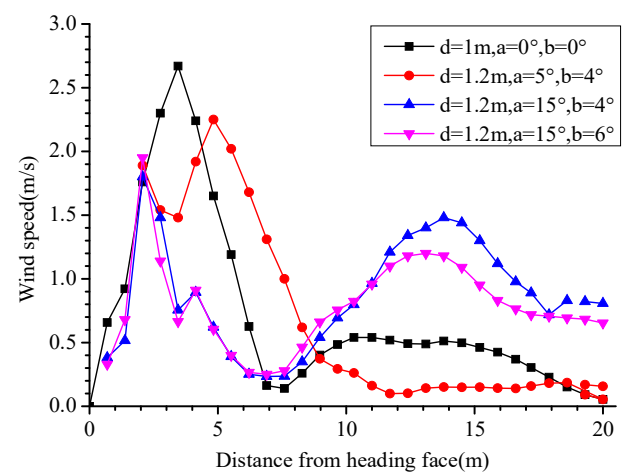

(a) Air velocity distribution at backflow side

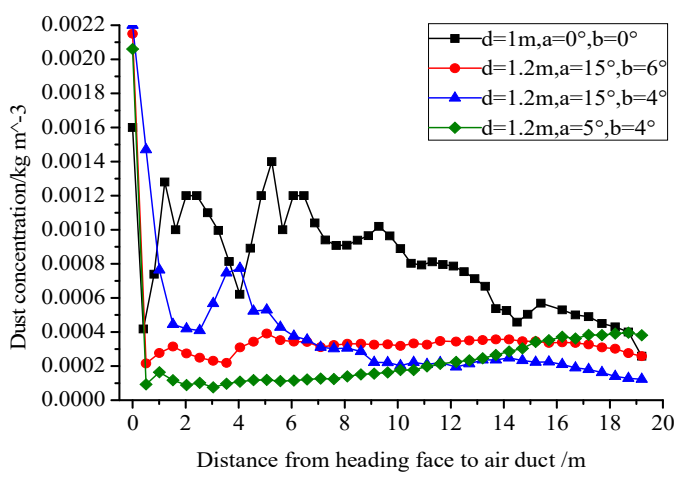

(c) Dust concentration at backflow side

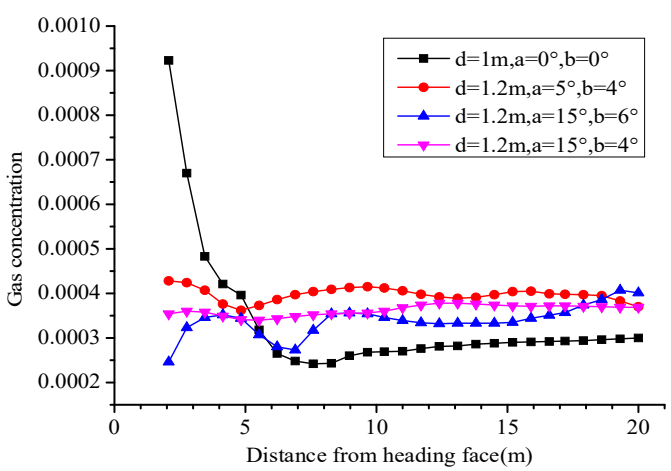

(b) Gas concentration at backflow side

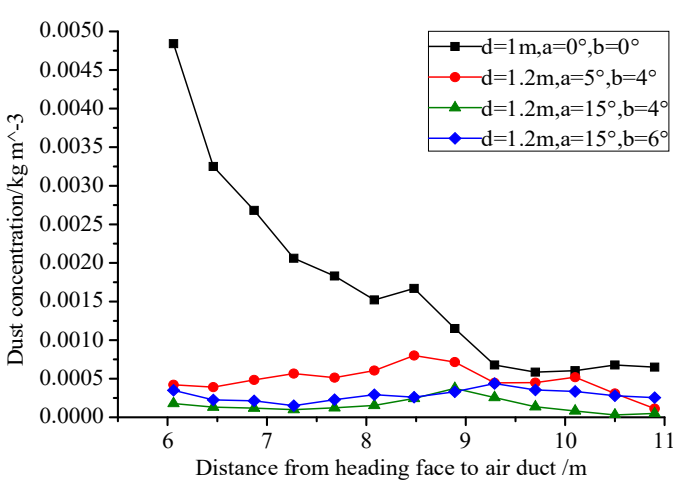

(d) Dust concentration at driver position

Figure 15. Air-flow, dust and gas distribution under different adjustment scheme (d-caliber, aright-skewed angle value, b-up-skewed angle value)

As shown in Figure 15, when the caliber of outlet is $1.2 \mathrm{~m}$ and the angle is at rightskewed $15^{\circ}$ and up-skewed $6^{\circ}$, the impact force of air-flow on heading face is reduced, and the problem of ventilation at dead corner is solved thanks to the larger caliber of outlet. Compared with other scheme, the gas concentration can be decreased from $0.1 \%$ to $0.023 \%$ and the air velocity is at $0.3-2 \mathrm{~m} / \mathrm{s}$ in the return side. The dust concentration at the air return side is substantially reduced (the lowest concentration is $0.01 \%$ ), indicating that environment for drivers has signifcantly been improved.

The scheme of caliber $1.2 \mathrm{~m}$ at the right-skew of $15^{\circ}$ and up-skew of $6^{\circ}$ can effectively improve the airflow field. Compared with the original air duct, when the caliber is extended, the impact force of airflow on heading face is reduced, especially adjusting the angle of outlet at the right-skew of $15^{\circ}$ and up-skew of $6^{\circ}$ is conducive to breaking vortex and solving the ventilation problem in the dead area. And at velocities ranging of $0.3-2 \mathrm{~m} / \mathrm{s}$, the gas concentration is declined from $0.1 \%$ to $0.023 \%$ and the dust concentration is greatly reduced.

As shown in Figure 16, the dust particle size distribution is uniform at distances of 0$10 \mathrm{~m}$ from the heading face. At distances of $15-20 \mathrm{~m}$, the large-sized particles begin to settle down, and the quantity of small-sized particles accounts for majority, especially presenting the larger percentage of respirable dust (particle size $<7 \mu \mathrm{m}$ ). From 
Figure 16, we can see that dust concentration is much lower, which reduces the harm for workers.

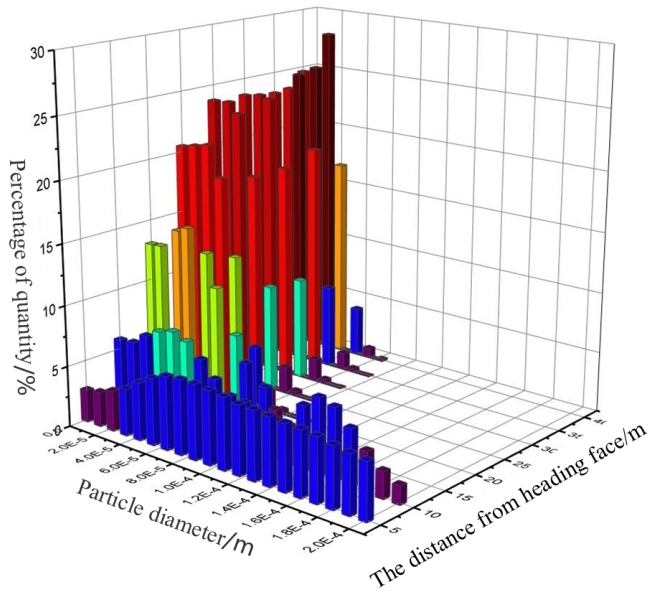

Before

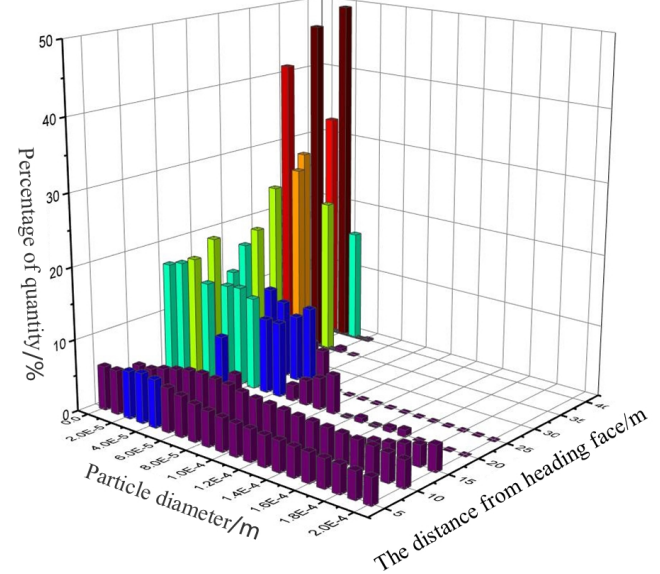

After

Figure 16. Comparison of particle size distribution in roadway

Using the same method above, the distribution of dust and gas at different distances $(6,7,8,9$ and $10 \mathrm{~m})$ between the outlet and heading face is comprehensively optimized, and the corresponding adaptability optimization adjustment method for air-flow is obtained, as shown in Table 7.

Table 7. Optimization adjustment scheme

\begin{tabular}{|c|c|c|c|c|}
\hline $\begin{array}{c}\text { Distance from } \\
\text { heading face }\end{array}$ & Adjustment scheme & $\begin{array}{c}\text { Velocity of air duct } \\
\text { side }\end{array}$ & $\begin{array}{c}\text { Dust concentration } \\
\text { at driver position }\end{array}$ & $\begin{array}{c}\text { Gas concentration } \\
\text { at upper corner }\end{array}$ \\
\hline $5 \mathrm{~m}$ & $\mathrm{~d}=1.2 \mathrm{~m}, \mathrm{a}=15^{\circ}, \mathrm{b}=6^{\circ}$ & $\begin{array}{l}\text { Reduced by } 60 \% \text { at } \\
\text { end of the jet-flow }\end{array}$ & Reduced by $35 \%$ & Reduced by $26 \%$ \\
\hline $6 \mathrm{~m}$ & $\mathrm{~d}=1 \mathrm{~m}, \mathrm{a}=15^{\circ}, \mathrm{b}=2^{\circ}$ & $\begin{array}{l}\text { Increased by } 30 \% \text { at } \\
\text { front of roadheader }\end{array}$ & Reduced by $30 \%$ & Reduced by $28 \%$ \\
\hline $7 \mathrm{~m}$ & $\mathrm{~d}=1 \mathrm{~m}, \mathrm{a}=10^{\circ}, \mathrm{b}=2^{\circ}$ & $\begin{array}{l}\text { Increased by } 27 \% \text { at } \\
\text { right of air duct }\end{array}$ & Reduced by $29 \%$ & Reduced by $30 \%$ \\
\hline $8 \mathrm{~m}$ & $\mathrm{~d}=1 \mathrm{~m}, \mathrm{a}=5^{\circ}, \mathrm{b}=2^{\circ}$ & $\begin{array}{l}\text { Increased by } 31 \% \text { in } \\
\text { front of air duct }\end{array}$ & Reduced by $31 \%$ & Reduced by $32 \%$ \\
\hline $9 \mathrm{~m}$ & $\mathrm{~d}=0.8 \mathrm{~m}, \mathrm{a}=10^{\circ}, \mathrm{b}=6^{\circ}$ & $\begin{array}{l}\text { Increased by } 56 \% \text { at } \\
\text { front of roadheader }\end{array}$ & Reduced by $29 \%$ & Reduced by $54 \%$ \\
\hline $10 \mathrm{~m}$ & $\mathrm{~d}=0.8 \mathrm{~m}, \mathrm{a}=5^{\circ}, \mathrm{b}=4^{\circ}$ & $\begin{array}{l}\text { Increased by } 65 \% \text { at } \\
\text { front of roadheader }\end{array}$ & Reduced by $28 \%$ & Reduced by $48 \%$ \\
\hline
\end{tabular}

\section{Conclusion}

The caliber, angle and the distance from the outlet to heading face of the duct outlet have a certain influence on the air, dust and gas field distribution in the fully mechanized heading face. The caliber adjusting of outlet can change the effective range of airflow as well as wind the velocity of duct outlet; the angle adjusting can change the direction of wind flow, which effectively solves the problems of dust and gas accumulation and ventilation in dead corner area; different distances from outlet to 
heading face have different requirements for parameters adjustment of outlet. According to the dust and gas migration law under different distances from duct outlet to heading face, the outlet parameters are adjusted using the method of airflow adaptability. The results show that the airflow adaptability adjustment not only improves the ventilation efficiency but also reduces the dust and gas accumulation to improve the environmental conditions for miners.

Through the numerical simulation analysis of the existing problems in the air, dust and gas field, the airspeed, gas concentration and dust concentration at the side of air duct are higher than that at the backflow side. The gas is easily accumulated at the upper and lower corners of the backflow side of heading face and near the heading machine, which causes dust accumulation and more attention should be paid.

Taking Ningtiaota coal mine in Northern Shaanxi of China as an object for practical application, the airflow, dust and gas field in the fully mechanized heading face was optimized comprehensively. The optimized simulation results were compared with those of the original field. Then the various optimization adjustment schemes were obtained at the different distances from the duct outlet to heading face. The dust concentration at the at driver position was decreased by $35 \%$ and the gas concentration reduced by $54 \%$ after the optimization. When the duct outlet is at the distance of $5 \mathrm{~m}$ from the heading face, the caliber of outlet should be expanded to $1.2 \mathrm{~m}$, which can rationally decrease airspeed at duct outlet. When the air outlet is at the distance of 9-10 $\mathrm{m}$ from the heading face, the outlet should be necked to $0.8 \mathrm{~m}$ to increase the effective range of airflow.

Acknowledgements. The authors would like to acknowledge the support of Shaanxi Science Research and Development Program Project (2017GY-170) and Education Department of Province Shaanxi Government Industrialization Cultivation Project (Control Technology and Device Development With Air Adaptation for Dust Deposition and Gas Declined).

\section{REFERENCES}

[1] Alam, M. M. (2006): An Integrated Approach to Dust Control in Coalmining Face Areas of a Continuous Miner and Its Computational Fluid Dynamics Modeling. - Southern Illionis University at Carbondale.

[2] Candra, K. J., Pulung, S. A., Sadashiv, M. A. (2014): Dust dispersion and management in underground mining faces. - International Journal of Mining Science and Technology 24(1): 39-44.

[3] Geng, F., Luo, G., Wang, Y. C. et al. (2018): Dust dispersion in a coal roadway driven by a hybrid ventilation system: A numerical study. - Process Safety and Environmental Protection 113: 388-400.

[4] Gong, X. Y., Qin, S. N., Zhang, Y. Q. et al. (2017a): Study on optimization of air duct outlet parameters of wind flow field in fully mechanized excavation face of coal mine. Safety in Coal Mines 48(12): 168-171.

[5] Gong, X. Y., Mo, J. M., Xue, X, Y., Xue, H. (2017b): Analysis on influence of fractal characteristics on distribution and settlement of dust flow in heading face ventilation. Coal Technology 36(09): 112-114.

[6] Li, Z. (2016): Influence of radial outlet angle of fresh air on dust control at fully mechanized excavating face. - Safety in Coal Mines 47(7): 190-192.

[7] Liu, H., T. (2010): Numerical Simulation of Micro-particle Deposition and Diffusion Characteristics in Gas-Solid Two-Phase Flow. - Chongqing University, Chongqing, China. 
[8] Liu, R. H., Wang, H. Q., Shi, S. L. et al. (2002): Study on regularity of dust distributing in heading face with forced ventilation. - Journal of China Coal Society 27(3): 233-236.

[9] Luo, Y. Zhao, Y. Wang, Y. et al. (2015): Distributions of airflow in four rectangular section roadways with different supporting methods in underground coal mines. Tunnelling \& Underground Space Technology 46(46): 85-93.

[10] Tang, Y., Wang, D. M., Wang, H. T. (2015): Numerical simulation on dust concentration on fully mechanized coal face. - Coal Technology 34(8): 203-205.

[11] Wang, H. Q., Shi, S. L., Liu, R. H. et al. (2004): Numerical simulation study on ventilation flow field of wall-attached jet in heading face. - Journal of China Coal Society 29(4): 425-428.

[12] Wang, K., Guo, H. G., Wang, F., Liu, R. Z., Cao, W. P. (2015): Dust movement rule in ventilators with different diameters in full-mechanized driving face. - Coal Mining Technology 20(05): 80-83+69.

[13] Wang, Z., Ren, T. (2013): Investigation of airflow and respirable dust flow behaviour above an underground bin. - Powder Technology 250(12): 103-114.

[14] Whang, H. Q. (1999): Study on jet ventilation flow field in heading face. - Journal of China Coal Society 5: 498-501.

[15] Zan, J., Liu, D. Z., Zhao, Y. S. (2010): Influence of characteristic parameters of restricted attachment jet on flow field in blind drift. - China Safety Science Journal 20(3): 24-28.

[16] Zhang, D. M., Ma, Y. D., Luo, G. H. (2016): On the effective range of the outlet from the flowing ventilation to the mechanized excavation face. - Journal of Safety and Environment 16(4): 186-191.

[17] Zhou, G., Zhang, Q., Bai, R., et al. (2017): The diffusion behavior law of respirable dust at fully mechanized caving face in coal mine: CFD numerical simulation and engineering application. - Process Safety \& Environmental Protection 106: 117-128.

[18] Zhou, X. M., Tang, M. B. (2014): Numerical simulation research on the influence of restricted jet structure parameters to ventilation flow field. - Modern Mining 30(5): 95-97. 